\title{
Organização Ética: um Ensaio sobre Comportamento e Estrutura das Organizações
}

\author{
Decio Zylbersztajn
}

\section{Resumo}

O presente ensaio discute o tema da ética nas organizações sob a ótica da Nova Economia Institucional. Ao lado de destacar a importância do comportamento ético e da responsabilidade social para as organizações, o estudo indica que as prescrições, com base na atitude benigna dos agentes, pode induzir problemas para as organizações em um ambiente concorrencial. O estudo explora a questão da sustentatibilidade da atitude ética e da necessária criação de mecanismos organizacionais para a sua implementação. O estudo analisa o conflito entre acionistas e stakeholders, discute os códigos de ética nas organizações e o papel do Estado como redutor de custos de transação.

Palavras-chaves: ética; organizações éticas; responsabilidade social.

\section{Abstract}

The main objective of the essay is to discuss the theme of ethics and organizations under the lenses of the New Institutional Economics. Given the importance of ethics and social responsibility for organizations, the study suggests the risk associated to the benign approach of cooperation based on the assumption of absence of opportunism. Also discusses the problem of survival of the ethical corporation, in face of the existence of non-ethical behavior of the competition. The study concludes that internal organization should be architected to provide the incentives and align the behavior of stakeholders and stockholders. It also concludes that institutional evolution should affect the capacity for the socially responsible organization survive in the market place.

Key words: ethics; ethical corporation; social responsibility. 


\section{INTRODUÇÃO}

Grande número de estudos sobre ética e responsabilidade social tem seguido a vertente normativa que toma como dado o pressuposto de que atitudes éticas trazem sempre vantagens para as organizações, além de colocarem acima de disputa a necessidade de atitudes altruístas. Se, por um lado, tal pressuposto reflete o desejo de construir um ambiente empresarial cooperativo, por outro, pode mascarar estratégias oclusas, colocando em risco aqueles que seguirem prescrições normativas sem sentido crítico. A contribuição central do presente ensaio é a de criticar o enfoque normativo naïve, recolocando o tema sob a ótica da Nova Economia Institucional, uma das vertentes que dão base ao moderno estudo das organizações.

O tema da responsabilidade social ganha espaço na agenda dos estudiosos das organizações públicas e privadas, bem como das organizações não-governamentais. Multidisciplinar por natureza, a análise da ética nas organizações tem sua importância ressaltada primeiro pelo crescimento e pela transnacionalização das organizações e segundo pela ampliação dos limites das firmas motivada pelo comportamento dos agentes. O tema é também avaliado quanto aos custos sociais, quando leis e normas coletivas são necessárias para pautar o comportamento dos indivíduos. Pode-se dizer que a primeira abordagem tem por base o trabalho de Coase (1937) e possibilita analisar o ambiente interno das organizações; a segunda baseia-se nos trabalhos de North (1990) e focaliza as macroinstituições representativas do ambiente externo das organizações.

Há controvérsias quanto ao tratamento dado pelos cientistas das organizações ao tema do relativismo ético, o que implica padrões culturais que influenciam as escolhas dos indivíduos na sociedade.

No presente estudo, objetiva-se explorar a vertente da Economia das Organizações baseada na Nova Economia Institucional e contrastar conceitos propostos por autores na área das ciências sociais aplicadas às organizações. Propõese que as organizações operam em situação de custos de transação positivos em presença da possibilidade de ações oportunistas, ressaltando-se a importância de arquitetar as organizações com estruturas aptas a controlar o comportamento dos agentes, em contraste com as propostas da vertente que objetiva alterar esse comportamento. Considerando o estado da literatura, as contribuições deste estudo podem ser assim descritas: 
- propor a Nova Economia Institucional como ferramenta útil para a análise do comportamento ético nas organizações;

. remover a análise da responsabilidade social do universo normativo, ressaltando a importância da análise positiva para os cientistas das organizações;

- ressaltar a necessidade de ampliação dos estudos sobre responsabilidade social para além das organizações com objetivos de lucro, incluindo as organizações não-governamentais e o próprio Estado.

Na segunda parte do estudo será aprofundada a discussão sobre o papel das organizações e dos mercados, apresentando-se o conflito entre acionistas e stakeholders ${ }^{(1)}$. Na parte seguinte serão aplicados os conceitos da Nova Economia Institucional, propondo-se a análise contratual das organizações como base analítica. Duas vertentes serão discutidas, a do ambiente econômico institucional externo à organização e a do ambiente interno à organização. No quarto tópico serão analisados aspectos aplicados da ética nas organizações, em especial os códigos de conduta e outros exemplos encontrados na literatura. Finalmente, na última parte, serão apresentadas as conclusões.

\section{Ética, Organizações e Mercados}

A ética nos negócios vem sendo tratada normativamente, com especial ênfase nas empresas privadas, prescrevendo-se os limites para as ações das organizações. Neste estudo, mantém-se que o tema deve ser ampliado para tratar as ações do Estado e das organizações não-governamentais, aspecto esse apontado por Arruda (2000), uma vez que não se pode assumir a ausência de oportunismo por parte de seus gestores.

Ética é definida como o "estudo dos juízos de apreciação referentes à conduta humana suscetível de qualificação do ponto de vista do bem e do mal, seja relativamente a determinada sociedade, seja de modo absoluto" (Ferreira, 1998, p. 733). A distinção entre as dimensões moral e ética é tratada por Rosansky (1994), que considera a primeira como um ato individual e a segunda como um princípio organizacional. O autor define ética como "uma tentativa de sistematizar as noções correntes de certo e errado, com base em algum princípio básico” (Rosansky,1994, p. 46).

A literatura sobre o tema sugere tratamento distinto para os problemas morais individuais e éticos, pertinentes às organizações, distinção essa central para o presente estudo. 
Mesmo que a questão do relativismo ético pudesse ser resolvida a partir de um padrão cultural comum, caberia perguntar como as organizações podem ser incentivadas a adotar padrões éticos. Se o comportamento aético adiciona custos às transações, por nem sempre ser alcançada a cooperação voluntária, quais são as prescrições que podem ser feitas para mitigar o problema, seja na esfera privada, seja na pública? Como as sociedades, e dentro delas as organizações, podem ser induzidas a incorporar princípios éticos?

Lewis e Wärneryd (1994) criticam os cursos de Administração por negligenciarem o tema e apontam a tendência de retomada da sua importância nas escolas de negócios. Também Berenbeim (1999) afirma que, crescentemente, as escolas de negócios estão incluindo aspectos de ética e métodos analíticos correlatos nos curricula de Administração. Tanto Lewis e Wärneryd (1994) como Berenbeim (1999) criticam os economistas neoclássicos, por eles tenderem a negligenciar outros aspectos comportamentais que não o da maximização dos lucros. North (1990, p. 15) ressalta, referindo-se ao pressuposto neoclássico da maximização de lucros: "como a literatura em economia experimental demonstra, o comportamento humano é claramente mais complexo do que o representado por esta pressuposição comportamental simplista".

\section{Economia e Ética}

A relação entre os princípios morais e éticos e a eficiência dos mercados e organizações está afeita ao conteúdo da teoria econômica e à ciência das organizações. A visão dos economistas a respeito da responsabilidade social está longe de ser unânime. Em geral, principiam da análise do comportamento maximizador individual, a partir do qual Smith (1904) constrói o conceito da eficiência dos mercados. Assim, Friedman (1962) considera que a missão social da corporação é a de realizar tanto lucro quanto for possível, em conformidade com as regras estabelecidas pela sociedade. A firma não tem outra obrigação social, a não ser a de maximizar o lucro dos seus acionistas. $\mathrm{O}$ autor assume que os custos informacionais são negligenciáveis e que há comportamento maximizador benigno dos agentes econômicos.

Demsetz (1995) coloca, ao discutir o oportunismo, que os aspectos éticos são importantes, mas que se deve ter cuidado ao introduzi-los. Conclui afirmando que “a análise econômica não faz e nem precisa fazer pressuposições acerca do comportamento ético. A análise depende apenas da pressuposição de maximização do lucro" (Demsetz, 1995, p. 28).

Arrow (1974), por sua vez, considera que os conceitos de ética e moralidade não são inconsistentes com os pressupostos do auto-interesse e do comporta- 
mento maximizador neoclássico. Assim, a economia é aplicável a áreas díspares, como a criminalidade, o matrimônio, e outros campos do comportamento social e econômico.

Sen (1987) critica a economia neoclássica, dizendo que ela se distanciou da ética ao não considerar os princípios motivacionais presentes na análise de Smith baseada nos sentimentos e comportamentos. O autor argumenta que os economistas constroem modelos simplistas baseados nas motivações facilmente caracterizáveis dos agentes econômicos, privilegiando a modelagem e distanciando-se da realidade. Nesse ponto, Sen e North, dois Prêmios Nobel de Economia, estão de pleno acordo(2), discordando de Friedman, outro Nobel. Da mesma forma que Arrow, Sen admite que a teoria econômica pode incorporar os conceitos da ética, e o faz em diferentes proporções, enquanto Friedman se atém aos aspectos de legalidade, assumindo que não existem falhas ou que o sistema de Justiça funciona a custo zero.

Etzioni (1988) é mais radical na crítica, ao considerar que a teoria econômica moderna ignora a dimensão moral e ética, alinhando-se mais a Sen (1987) em sua postura. Análises complementares podem ser vistas em Buchholz (1989) e Hartley (1993). Revisão sobre o tema aparece em Bianchi (1998), que concluiu ser "necessário rever o papel da racionalidade egoísta nos modelos econômicos”.

No presente estudo, vêem-se as organizações operando com custos de transação positivos, distanciando-se da visão de Friedman (1962), mas considera-se a presença do oportunismo, distanciando-se da visão de Sen (1987). Ressalta-se ser importante arquitetar as organizações com estruturas aptas para lidar com o comportamento dos agentes.

\section{Ambiente Competitivo: o Conflito entre Acionista e Stakeholder}

A análise econômica tradicional trata da corporação socialmente responsável, ou como um desvio do objetivo maximizador de lucro, ou como resultado de ampliação da função de utilidade dos acionistas que incorporam outros elementos além do lucro. Interpretando o primeiro elemento, a empresa que operar em ambiente competitivo terá de sobreviver em um mercado em que nem todas as empresas atuam conforme os mesmos princípios éticos.

O segundo elemento considera o grau de concentração acionário. Caso existam inúmeros pequenos acionistas, ou no caso de o acionista ser um fundo de investimentos, fica mais difícil identificar uma função de utilidade que não privilegie o retorno econômico puro e simples induzindo a recomposição do portfólio de ações. 
Brickley, Smith e Zimmerman (1997) observam que se a firma tiver o seu valor reduzido, isso colocará em risco a sua sobrevivência no longo prazo. Certamente, em ambientes econômicos estruturados com sistemas legais eficientes, as organizações tenderão a ter um padrão de concorrência normatizado, reduzindo o escopo para ações oportunistas.

\section{O Papel do Stakeholder}

Os stakeholders são os não-acionistas, envolvidos direta ou indiretamente com a operação da organização. Segundo Berenbeim (1999), são eles os empregados, os clientes, os fornecedores e a comunidade local. As organizações poderão ter incentivos para adotar estratégias que beneficiem os stakeholders, o que irá resultar na redefinição dos direitos de propriedade sobre os resíduos gerados.

Em alguns casos, os stakeholders adquirem direitos legais, o que obriga as organizações a adotar medidas de cooperação, como no caso dos direitos sociais dos trabalhadores. Há situações que se caracterizam pelo ato cooperativo espontâneo entre a organização e a sociedade movida por outros incentivos. Enquadram-se nesse caso as cooperações com entidades filantrópicas locais e as promoções sociais de diferentes naturezas. Essas ações serão justificadas pela ótica maximizadora, sempre que a empresa se beneficie de um ambiente positivo, que possa gerar acréscimo no valor da organização no longo prazo. Em outros casos podem significar um desvio entre as funções-objetivos do acionista e do gerente, o que configura um problema de agência. Essa questão é tratada por Jensen (2000) e Pinheiro Machado (2002), que indicam o risco associado à dispersão de recursos, quando as ações sociais não são amparadas por adequados controles internos. Finalmente, elas podem resultar de uma proposta dos acionistas, que derivam utilidade a partir de postura socialmente valorizada pelos stakeholders.

\section{Falhas de Mercado}

A análise dos incentivos para a produção de normas de cooperação entre os agentes econômicos pode ser feita com base no conceito de falha de mercado. Normas de comportamento ético podem ser vistas como bens públicos, que apresentam as características de não rivais e não exclusivos. Essa vertente analítica permite derivar conclusões sobre a produção exagerada de externalidades negativas, e está presente em Tomer (1994), Wieland (1994) e Posner (1999). Esses autores colocam o problema da falta de produção de normas éticas como decorrente de falhas de mercado. Tomer (1994) conclui que os economistas treinados na ortodoxia são incapazes de apreciar argumentos que considerem a responsabilidade social das organizações, desenvolvendo também o argumento da doutri- 
na da firma responsável, que é vista como forma alternativa de controle oferecido pelo mercado ou pelo governo. Tal vertente busca explicar a ação voluntária das organizações a partir da existência de um contrato social implícito entre a organização e o grupo representado pelos stakeholders. Explicita os custos de não atuar de modo cooperativo, propondo outros incentivos além do lucro. As organizações implementam estratégias que as comprometem com uma relação harmoniosa com o ambiente social, que interfere positivamente no seu valor.

Até que ponto uma organização tem incentivos para agir eticamente é uma questão aberta. A visão de Tomer (1994) assume que a taxa de desconto intertemporal é baixa ou zero, ao não considerar o ambiente competitivo no curto prazo. Em outras palavras, se os benefícios da ação cooperativa só puderem ser colhidos no longo prazo, talvez a firma não sobreviva para colhê-los.

O debate econômico importa para a ciência das organizações, pois dele decorrem aspectos prescritivos; entretanto tende a não relevar tanto as instituições como as estruturas organizacionais para lidar com os problemas advindos de ações aéticas relacionadas a assimetrias informacionais e comportamento oportunístico, dimensões essas exploradas a seguir.

\section{A Contribuição da Nova Economia Institucional}

Brickley, Smith e Zimmerman (1997) afirmam que ética e arquitetura das organizações são conceitos relacionados. Da mesma forma, cabe ressaltar que a ética e o ambiente institucional são fortemente relacionados. Desconsiderar o papel da arquitetura das organizações e das instituições pode levar a erros na prescrição de soluções para os problemas das organizações e no desenho de políticas públicas.

\section{As Contribuições de Coase e Simon}

A contribuição de Coase (1937) para a teoria econômica teve desdobramentos importantes para a ciência das organizações. A proposição de que o funcionamento dos mercados tem um custo adicionou importante elemento à compreensão tanto dos mercados como das organizações. Os custos de transação têm natureza diferente das causas das falhas de mercado.

A firma surge como uma resposta otimizadora dos agentes econômicos, quando os custos da organização dos contratos pela via do mercado excedem os custos da organização interna. Coase (1937) trata a firma não como estereótipo 
da função de produção, mas como conjunto de contratos entre agentes especializados, cujo gerenciamento tem um custo. Embora válido para muitos efeitos, o tratamento dado à firma pela teoria econômica neoclássica tem utilidade limitada para quem deseja estudá-la sob a ótica organizacional. Tal crítica foi explicitada por Coase (1991) em seu discurso ao receber o prêmio Nobel de Economia: “o que é estudado é um sistema que vive na mente dos economistas, mas não no mundo real. Eu chamo o resultado de [...] economia de quadro negro [...]. A firma estudada carece de qualquer substância, sendo tratada pela teoria como caixa preta”.

Quando assevera que firma e mercado são alternativas para a realização das transações, Coase (1937) abre o caminho para a compreensão da organização interna das firmas e dos mercados, além de permitir melhor compreensão das relações contratuais, formais e informais entre as firmas. O seu trabalho amplificou o estudo do crescimento das organizações, com grande aplicabilidade para a compreensão da tendência de fusões, aquisições, alianças estratégicas, subcontratações, entre outros tópicos.

Especialmente voltado para o estudo das organizações, Simon (1947, 1972a, 1972b) contribui com a análise da racionalidade limitada e as suas ligações com a teoria comportamental das organizações. Segundo Williamson (1996), aluno de Simon na Carnegie Mellon University, o conceito de racionalidade limitada é central para a moderna economia das organizações.

Simon (1972b) define racionalidade limitada como o comportamento que objetiva ser racional, mas que apenas consegue sê-lo parcialmente, estabelecendo um conflito com o pressuposto de hiper-racionalidade da economia neoclássica. É classificada como forma semiforte de racionalidade, em contraste com a racionalidade forte centrada na maximização do lucro, que caracteriza a escola neoclássica, e a racionalidade orgânica, que caracteriza a escola evolucionista.

Os contratos definidos entre os agentes econômicos são incompletos, uma vez que não existe a capacidade de antecipar todas as contingências futuras. Se fosse possível desenhar contratos completos, não existiria problema para as organizações se estruturarem e os problemas gerados a partir do comportamento aético seriam antecipados e tratados com cláusulas de salvaguarda.

O conflito entre a ortodoxia e a Nova Economia Institucional pode ser relativizado, quando se afirma que a economia ortodoxa foi desenhada para estudar o funcionamento dos mercados e o papel dos preços, e não o papel, a estrutura e a operação das organizações. A tal enfoque sobrepõe-se o conceito coasiano dos custos do funcionamento dos mercados, para marcar nitidamente o objeto de um novo campo para o estudo das organizações. 
Se as organizações podem ser entendidas como um nexo de contratos, o comportamento dos agentes que são partícipes dos contratos, bem como o das instituições que os garantem, assume grande importância. O comportamento cooperativo e benigno, quando contrastado com o comportamento oportunista, terá conseqüências para o desenho das organizações; daí a sua ligação com a ética nas organizações. A dicotomia organizações-instituições representa o principal desenvolvimento pós-coasiano, gerando uma família de teorias que lidam com as organizações, entre as quais a teoria do agente-principal (de raiz neoclássica), a teoria dos incentivos e a economia dos custos de transação. Neste estudo serão tratadas duas vertentes que compõem o que hoje se denomina de Nova Economia Institucional, a economia dos custos de transação de Williamson $(1975,1996)$ e a teoria de evolução institucional de North (1990), ligando-as ao tema da ética.

\section{O Oportunismo e a Contribuição de Williamson}

Partindo de Coase (1937), Williamson (1975) desenvolveu uma teoria aplicada ao estudo das organizações. Basicamente, utiliza dois pressupostos comportamentais - o da racionalidade limitada de Simon (1972b) e o seu corolário, os contratos incompletos - que, associados ao pressuposto do oportunismo, fornecem as bases para a análise das formas de governança das organizações.

A teoria das organizações, influenciada por Williamson (1975), parte do pressuposto de que os agentes econômicos podem não agir benignamente, tendo uma orientação calcada na busca do auto-interesse, colocando formações, voltadas para a obtenção de benefícios próprios. O autor não afirma que todos os agentes são oportunistas o tempo todo, mas que alguns podem sê-lo em algum momento, o que será suficiente para a demanda de respostas organizacionais. Na presença de oportunismo, assumindo racionalidade limitada e contratos incompletos, os custos pós-contratuais serão reduzidos, se salvaguardas apropriadas forem definidas ex-ante.

A intensidade dos incentivos para criar formas apropriadas de governança para as transações está ligada ao grau de exposição às perdas dos agentes econômicos, que se engajam em contratos de longo prazo. A especificidade dos ativos é introduzida por Williamson (1996) para designar a perda de valor dos investimentos no caso de quebras oportunísticas dos contratos. Em outras palavras, considerando a existência de oportunismo, de contratos incompletos e na presença de ativos específicos, as organizações deverão responder, criando estruturas que permitam a sobrevivência dos contratos no longo prazo.

Na ausência de oportunismo e com racionalidade plena, tem-se o mundo da utopia, no qual nenhuma estrutura organizacional seria demandada e as promes- 
sas seriam sempre cumpridas. Assumindo ausência de oportunismo e presença de racionalidade limitada, a negociação benigna resolveria os problemas das organizações. Assumindo oportunismo e racionalidade plena, os problemas organizacionais teriam solução pelo desenho antecipado de salvaguardas e pelo desenho de contratos compreensivos.

A proposta da Economia dos Custos de Transação é a de que o mundo real se enquadra na situação de racionalidade limitada e presença potencial de oportunismo, demandando o desenho de estruturas especializadas para governar as transações, a partir do tipo de especificidade de ativos. Estruturas de monitoramento e de controle precisam ser desenhadas para permitir que os agentes lidem com os riscos potenciais de ruptura contratual. Há custos envolvidos com a criação de mecanismos de desenho, monitoramento e controle nas organizações, os quais são denominados de custos de transação.

O problema do agente-principal pode ser tratado como questão contratual, segundo a qual os agentes atuam de modo desalinhado com os interesses do principal. Jensen e Meckling (1976) definem o custo de agência como a soma dos custos para monitorar e limitar a ação do agente e do valor residual perdido pelo principal. Trata-se de um desalinhamento causado por assimetria informacional entre o agente e o principal, o qual demanda estruturas contratuais especializadas. Difere do tratamento da Economia dos Custos de Transação de Williamson (1975), pois prescreve soluções contratuais ótimas ex-ante, enquanto o segundo enfoque mantém que os contratos são incompletos e, assim, não podem emergir soluções que ignorem a possibilidade do oportunismo pós-contratual.

Mais recentemente, Jensen (2000) retoma a questão da agência, analisando a firma socialmente responsável sob a ótica do conflito entre as preferências dos acionistas e dos stakeholders, mais uma vez indicando a necessidade de estruturas especializadas para controlar o problema de agência.

\section{Ambiente Econômico Institucional: a Contribuição de North}

A contribuição de North (1990) também deriva da influência de Coase (1937), mas diferencia-se do trabalho de Williamson (1975), por focalizar o papel das instituições econômicas, o seu desenvolvimento e a sua relação com as organizações. São centrais no seu trabalho tanto o papel das instituições como a mudança institucional. Basicamente, North (1990) define instituições como conjunto de leis, normas, costumes, tradições e outros aspectos culturais que pautam a ação de sociedades, organizações e indivíduos. Ressalta o papel das instituições, explorando a sua importância como redutoras dos custos de transação para a sociedade. Para o autor, “o maior papel das instituições na sociedade é o de reduzir 
as incertezas, estabelecendo uma estrutura estável (não necessariamente eficiente) para a interação humana” (North, 1990, p. 6).

Enquanto Williamson (1996) focaliza a análise microeconômica, North (1990) detém-se na análise macroeconômica, sendo o desempenho da economia afetado pelos custos de transação induzidos pela estrutura das instituições. A relação entre as instituições e as organizações proposta por Williamson (1996), coloca que as organizações afetam o ambiente institucional que, por sua vez, limita a ação das organizações. Essa análise permite a compreensão dos lobbies econômicos e grupos de pressão na sociedade, que interferem nas instituições em busca de rendas.

O trabalho de North (1990) parte da necessidade de códigos de conduta estruturados nas instituições, os quais servem como facilitadores do funcionamento da sociedade. Assume a latência, na sociedade, de conflitos que não são resolvidos de forma benigna e espontânea, mas carecem de estruturas institucionalizadas para a sua implementação. Não descarta a possibilidade de ineficiências nas instituições, consagradas por problemas de captura de agentes ou de falhas estruturais nos sistemas legais.

A persistência de instituições ineficientes está respaldada pela sua interação com as organizações. As instituições evoluem para limitar a ação das organizações e estas colocam pressão para mudar as instituições a seu favor. A persistência de estruturas ineficientes resulta da pressão dos grupos de interesse organizados na sociedade ${ }^{(3)}$. Isso explica o passo lento das reformas institucionais. North (1990) afirma que as instituições são criadas, evoluem e são alteradas pelos indivíduos; portanto a teoria de mudança institucional deve começar pelos indivíduos.

As instituições informais, os grupos religiosos, os costumes tribais, códigos de conduta aceitos pela sociedade, bem como a sua estrutura legal, fazem parte do universo das instituições focalizadas por North (1990). O risco de quebras contratuais oportunísticas será controlado à medida que os agentes percebam o risco de punições.

O surgimento das normas, a sua evolução e os incentivos para a sua obediência são importantes tanto para a análise microeconômia como para a macroeconômica. North (1990) explora os custos de identificação das quebras contratuais, da imputação da pena e da sua implementação como custos associados ao sistema legal.

A análise macroinstitucional privilegia o papel das cortes de Justiça (public ordering) para a solução dos problemas de quebras contratuais; ela é defendida 
por autores da área de Economia do Direito, embora também releve o papel da pressão social. Essa visão contrasta com o enfoque de Williamson (1996) que, sem ignorar o papel do ordenamento público, privilegia as organizações privadas para controlar o oportunismo (private ordering).

\section{Mecanismos de Controle}

A literatura sobre ética nas organizações pode ser dividida em duas vertentes, uma que privilegia os agentes e as possibilidades de interferir no seu comportamento espontâneo (Chanlat, 1992; Migliaccio Filho, 1994; Petrick e Quinn, 1998), e outra que privilegia o papel do ordenamento privado e público. No presente ensaio, mantém-se que a vertente focalizada na adequação das organizações e instituições é a que mais importa para os administradores e cientistas das organizações.

A pressuposição do comportamento cooperativo benigno, mais do que irrealista, pode levar a prescrições desastrosas para as organizações. Toda a literatura sobre confiança, como se encontra em Fukuyama (1995), é consistente ao assumir que a prosperidade resultaria da cooperação benigna, cabendo apenas discutir o realismo do pressuposto. Ressalta a ambigüidade existente entre a visão normativa e a visão positiva; no entanto é importante perceber a responsabilidade dos cientistas das organizações sobre os resultados das suas prescrições.

Faz-se necessário desenvolver um espectro dos mecanismos de controle das ações oportunistas e seus resultados para as organizações, para a análise que parta do indivíduo e chegue às macroinstituições.

\section{Mecanismos Baseados na Reputação}

Muitas vezes interpretados como cooperação benigna e não-oportunística, os mecanismos de reputação induzem a cooperação, sempre que existam transações repetitivas que envolvem os mesmos agentes. A ruptura oportunística dos contratos leva à perda do valor, descontado de um fluxo de rendas futuras, que incentiva os agentes à cooperação. O mecanismo de reputação é tratado por Milgrom e Roberts (1992), que ressaltam o fato de o efeito ser potenciado pela difusão da informação entre os agentes no mercado.

A indução da cooperação é tratada pela teoria dos jogos, ao considerar o surgimento de equilíbrio motivado por jogos repetitivos. É utilizada por Milgron e Roberts (1992) uma matriz de lucro com dois resultados distintos, um para o caso de jogo único, e outro para o caso de jogos repetitivos, nos quais emerge o incentivo à reputação do agente, induzindo um equilíbrio de $\mathrm{Nash}^{(4)}$. 


\section{Controle do Custo de Agency}

Os mecanismos de mercado podem alinhar as atitudes do agente com as do principal, desmotivando atitudes oportunistas. Da hipótese da perda do valor da empresa decorre o controle do agente. Segundo esse enfoque, as organizações utilizarão recursos para monitorar os agentes ou redefinirão o padrão de incentivos embutidos no desenho contratual.

\section{Autocontrole}

Esta forma de controle baseado na atitude individual altruística é consoante com a teoria normativa da ética e assume que os indivíduos podem mudar as suas preferências. Contratos baseados puramente na confiança entre os indivíduos representam formas frágeis de organização para garantir a sobrevivência no longo prazo. Posner e Rasmusen (1999) discutem o papel da culpa como forma de sanção automática, que induz os indivíduos a determinado comportamento, aqui considerado utópico. Esse enfoque redunda em esforços que visam à mudança das preferências individuais e, se funciona em casos particulares, a sua generalização passa pelo pressuposto de comportamento benigno.

\section{Controle no Grupo}

Formas de organização social dentro de grupos socialmente coesos são fartamente exploradas na literatura, revisada por North (1990). As cooperativas agrícolas formadas por grupos étnicos pequenos, tendem a ter estruturas de monitoramento mais reduzidas. As sanções existentes para os agentes oportunistas são resultantes da possível exclusão social, com impactos pecuniários e morais. Demsetz (1995) aborda o conceito de equipes (team work), no qual o problema do carona emerge a partir da atitude oportunística de um membro do time. Uma das formas de tratamento do problema é a da pressão do grupo como agente monitorador.

\section{Instituições Legais Formais}

Representam a forma institucionalizada mais estruturada para lidar com o oportunismo. Incorporam os aspectos culturais e éticos que predominam nas sociedades, podendo evoluir de acordo com as mudanças presentes no tecido social. Incorrem em custos de funcionamento e têm papel sinalizador. North (1990) parte desse ponto para explicar diferentes padrões de desenvolvimento das economias, conclu- 
indo que o papel sinalizador das instituições tem efeito redutor dos custos de transação advindos de atitudes oportunísticas controladas pelo aparato institucional.

\section{Normas Sociais}

São exploradas por Posner e Rasmusen (1999) e representam um capítulo tão, ou mais, complexo quanto o das leis formais. Os autores exploram o tema, considerando os custos de implementação e o papel das sanções, que vão desde as automáticas para as infrações das convenções, como dirigir na pista contrária, até as de autocontrole baseado em culpa ou as de controles pelo grupo, com base no risco de exclusão. As sanções têm papel sinalizador; apresentam uma dimensão para o agente e um custo para a sua aplicação, o que determinará a sua eficiência.

\section{Organizações}

Criam normas internas que representam custos para os agentes que rompem contratos. O risco de ser despedido, as multas ou as perdas de benefícios, são normalmente utilizados pelas organizações. Entre as estruturas criadas para lidar com o problema estão os códigos de comportamento, analisados adiante.

No presente tópico, buscou-se analisar o papel das organizações e instituições para o controle das ações oportunísticas. Destacou-se a ação coercitiva e o seu papel sinalizador, bem como o papel das organizações que se estruturam para lidar com o oportunismo potencial. Discutiu-se a importância de que os aspectos éticos, vistos como obediência às normas socialmente aceitas, sejam tratados com a criação e o desenho de estruturas organizacionais adequadas, que incentivem e monitorem as ações dos indivíduos. No próximo tópico serão discutidas algumas dessas estruturas.

\section{Aspectos Aplicados da Ética nas Organizações}

Os códigos de conduta são utilizados pelas organizações como forma de regular as ações dos agentes e alinhar a sua conduta com a dos acionistas. Esses códigos vêm sendo utilizados como indicadores da preocupação ética das organizações.

As estruturas tradicionais de monitoramento e controle existentes nas organizações, seriam menos necessárias se os agentes tivessem comportamento cooperativo, aderindo voluntariamente aos princípios corporativos. Como tal quadro não é realista, as organizações criam mecanismos de controle, que vão dos con- 
selhos de administração até os códigos estruturados de ética nas empresas. Assim, um código pode ser visto como contrato formal entre os acionistas e os stakeholders, com o objetivo designado de informar os agentes sobre as expectativas dos acionistas. Se há ou não incentivos associados, é a questão central neste estudo.

As empresas adotam códigos de ética por diferentes razões. Muitas vezes o código representa uma perspectiva distante da realidade da organização, existindo apenas como tentativa de criar uma imagem corporativa positiva ou mesmo para servir como salvaguarda legal, no caso de litígios na Justiça ${ }^{(5)}$. A efetiva adoção do código pode ser analisada a partir de uma perspectiva contratual, ou seja, com a identificação dos incentivos existentes na organização, desenhados para motivar a adoção do código.

Conforme estudo realizado por Berenbeim (1999), evidencia-se o crescente papel da mídia e de riscos de ações judiciais, o que incentiva a adoção de códigos. Assim, as organizações estão interessadas em evitar eventuais perdas de valor de reputação, causadas por escândalos ou mesmo ações judiciais. Por outro lado, no meio empresarial cresce a preocupação com estratégias que competidores menos escrupulosos possam ter, quando uma empresa isolada mantém conduta baseada em elevado padrão ético. $O$ autor identifica um conjunto de justificativas e incentivos para a adoção de códigos de ética, os quais serão analisados à luz dos conceitos apresentados no capítulo anterior.

\section{Justificativas para a Adoção de Códigos de Ética}

\section{Incentivos Legais}

Alguns países institucionalizaram diretrizes éticas mínimas para as organizações. Um exemplo, citado por Kaplan, Dakin e Smolin (1993), é o do U.S. Revised Organizational Sentencing Guidelines, de 1991, que impõe multas de até US\$ 40 milhões para organizações que falham na adoção de diretrizes para atos julgados indevidos, ainda que sejam da responsabilidade de um único empregado.

Essa estrutura de incentivos está alinhada com a análise de North (1990). Ela explicita a importância dos incentivos dados pelas instituições, em vez de esperar as ações cooperativas espontâneas.

\section{Crescente Internacionalização}

A atuação das organizações multinacionais provoca um dilema com respeito às 
normas a serem seguidas. Existe organizações que adotam as normas de cada país em que atuam e, na sua ausência, as do país de origem. Há casos de organizações que adotam apenas o código legal existente no país em que estejam operando.

\section{Riscos de Incidentes que Afetam a Reputação}

Aparentemente, o incentivo mais eficaz para a adoção de normas éticas ocorre sempre que exista risco potencial de efeito sobre o valor da empresa. Para se precaverem de tais riscos, muitas organizações adotam códigos de ética e certificação independentes, para aferir a sua credibilidade em relação à conduta ética voltada para aspectos sociais, ambientais e tecnológicos. A exposição na mídia também se alinha aos efeitos via perda de reputação, sendo reforçada pelo papel fiscalizador das organizações não-governamentais.

Brickley, Smith e Zimmerman (1997) consideram que os agentes identificam os custos e benefícios associados a cada alternativa. Os autores propõem que menos esforço seja alocado na seleção ou no treinamento e mais no provisionamento de incentivos corretos. A mesma conclusão aparece no estudo de Berenbeim (1999), quando afirma que os procedimentos éticos demandam incentivos para dar consistência aos princípios gerais apresentados pelas organizações.

\section{Ética e Coordenação Contratual}

O tema da coordenação da produção é central nas corporações. As firmas passam a ser vistas mais como um conjunto de contratos externos do que como estrutura de produção hierárquica, o que leva a problemas de coordenação entre organizações independentes.

Da mesma forma que a manutenção de padrões de qualidade, que resultam de complexas cadeias de produção, demandam estruturas de governança apropriadas, como mecanismos de certificação e normas internacionais, também a adoção de normas éticas pode demandar mecanismos certificadores acreditados; portanto surge o mercado para a certificação social.

O termo contract ethics aparece na literatura (Berenbeim, 1999) justamente para indicar a rejeição de práticas que envolvam propinas, pagamentos indevidos, conflito de interesses e uso de informação proprietária. Obviamente, a orientação para não fraudar deve ser acompanhada de ações definidas pela organização que punam os infratores.

Pode-se afirmar que os preceitos comportamentais implicam custos considerá- 
veis de transação, induzindo a necessidade de monitoramento, seleção dos agentes colaboradores, estruturação de mecanismos de incentivo e, em última análise, maior integração vertical.

\section{O Papel do Estado}

O Estado pode atuar como reforço aos incentivos mencionados, fazendo valer os direitos de propriedade implícitos nas leis, o que tem papel sinalizador. O Estado pode divulgar e utilizar as informações sinalizadoras dos agentes. Por exemplo, os agentes que descumprem contratos podem ser impedidos de participar de processos de licitações públicas.

Assim, ressalta-se a importância dada por North (1990) ao papel sinalizador das instituições; entretanto o elevado custo de operação das instituições legais acaba sinalizando a impunidade, com a criação de incentivos à desobediência de normas socialmente aceitas, por parte de agentes oportunistas.

Finalmente, o Estado pode acelerar o processo de mudanças e adequações institucionais, buscando adaptar normas e leis à realidade mutante da sociedade.

\section{Conclusões}

O comportamento ético representa um valor da sociedade moderna; no entanto existe falhas no comportamento ético dos indivíduos, das organizações e das sociedades. Todos os desvios possíveis e conhecidos do comportamento humano podem estar presentes nas organizações, sejam elas empresas, sejam organizações não-governamentais, seja o próprio Estado.

As organizações estão sujeitas aos custos advindos das quebras contratuais de agentes que cooperam para o seu funcionamento. A Economia dos Custos de Transação, como parte da Economia das Organizações, propõe que as estruturas organizacionais sejam desenvolvidas para lidar com o problema. Da mesma maneira, as instituições, vistas sob a ótica de North (1990), devem desenvolver-se como regras formalizadas em leis e códigos informais de conduta, que reduzirão os custos transacionais na sociedade.

O risco da adoção de uma visão benigna do comportamento humano foi tratado por Williamson (1996), ao afirmar que o mundo dos negócios seria enviesado para o benefício daqueles cujo comportamento é aético. Assim, soluções eficazes dependem do desenvolvimento das organizações e instituições; daí o papel 
dos cientistas das organizações. Mudanças nas atitudes dos indivíduos podem reforçar, mas não substituir as organizações e instituições, uma vez que esse é o papel de outras especialidades da atividade humana.

Amplo escopo de possibilidades abre-se para a investigação das relações éticas na sociedade, em especial em países cujas instituições legais são frágeis. Alinhado com a agenda neo-institucional apregoada por North, Coase e Williamson, o entendimento do processo de mudança institucional é um elemento-chave para o desenvolvimento da pesquisa na área da ética nas organizações. No plano das organizações cabe afirmar o mesmo. Quais os mecanismos de incentivo que podem ser arquitetados para mitigar, limitar e combater as ações oportunistas? Compreender melhor a arquitetura dos contratos implícitos que regem as relações entre as organizações pode ser a chave para o avanço da investigação.

Em relação ao ensino, a retomada do tema da ética nos programas das escolas de Administração, Economia e Direito pode trazer importante contribuição, em especial para os países em transição. Finalmente, é perceptível que, não necessariamente movidas por atitudes benignas e cooperativas, mas para manter o seu valor de reputação, as organizações tendam a preocupar-se crescentemente com o tema. Tanto as organizações privadas como os organismos públicos e as organizações não-governamentais terão, então, a sinalização das vantagens a serem colhidas no longo prazo.

\section{Notas}

\footnotetext{
${ }^{1}$ Como não foi encontrado termo equivalente consagrado na literatura em português, será mantido o termo inglês stakeholder, significando o conjunto de não-acionistas direta ou indiretamente afetados por determinada organização.

${ }^{2}$ Mais adiante será introduzida a opinião de outro Nobel, Ronald Coase, que tece a mesma crítica.

${ }^{3}$ Pode-se citar como exemplo a persistência do protecionismo agrícola na Europa, ainda que todos conheçam as ineficiências geradas.

${ }^{4}$ Ver Axelrod (1984) para um tratamento mais completo do tema.

${ }^{5}$ Em outras palavras, caso o empregado infrinja uma regra, não pode ser dito que foi por negligência da direção.
} 
RefERÊnCIAS Biblográficas

ARROW, K.

Limits of organization. New York: Norton, 1974.

ARRUDA, M. C. C.

Notas de palestra proferida no Seminário Ética nos Negócios, São Paulo, Fundação FIDS/Conselho Regional de Administração, 2000.

\section{AXELROD, R.}

The evolution of cooperation.

New York: Basic Books, 1984.

\section{BERENBEIM, R. E.}

Global corporate ethics practices: a developing consensus. Research Report 1243-rr, The Conference Board, [S.l.], 1999.

BIANCHI, A. M.

Anotações de uma pesquisa sobre economia e ética. In: SEMINÁRIO BRASILEIRO SOBRE A NOVA ECONOMIA INSTITUCIONAL, 1., 1998, São Paulo. Anais... São Paulo: Faculdade de Economia, Administração e Contabilidade da Universidade de São Paulo, 1998.

BRAYBROOKE, D.

Ethics in the world of business. [S.l.]: Rowman \& Littlefield Publishers, 1983.
BRICKLEY, J. A.;

SMITH JR, C. W.;

ZIMMERMAN, J. L.

Managerial economics and organizational architecture.

Chicago: Irwin, 1997.

BUCHHOLZ, R. A.

Fundamental concepts and problems in business ethics. Englewood Cliffs, NJ: PrenticeHall, 1989.

CHANLAT, J-F.

A caminho de uma nova ética das relações nas organizações. Revista de Administração de Empresas, v. 32, n. 3, p. 68-73, jul./set. 1992.

COASE, R. H.

The nature of the firm. Economica, v. 4, p. 386-405, 1937.

The institutional structure of production. Stockholm: Alfred Nobel Memorial Proze Lecture in Economic Sciences, 1991.

DEMSETZ, $\mathrm{H}$.

The economics of the business

firm: seven critical commentaries. Cambridge: Cambridge University Press, 1995. 
ETZIONI, A.

The moral dimension: toward a new economics. New York: The Free Press, 1988.

FERREIRA, A. B. de H.

Novo dicionário da língua portuguesa. 2. ed. rev. amp. Rio de Janeiro: Editora Nova Fronteira, 1998.

FRIEDMAN, M.

Capitalism and freedom. Chicago: University of Chicago Press, 1962.

\section{FUKUYAMA, F.}

Trust: the social virtues and the creation of prosperity. New York: The Free Press, 1995.

HARTLEY, R. F.

Business ethics: violations of public trust. New York: John Wiley \& Sons, 1993.

JENSEN, M. C. Value maximization, stakeholder theory and corporate objective function. Boston, Harvard Business School, 2000. Working paper 00-058.

JENSEN, M. C.;

MECKLING, W. H.

Theory of the firm: managerial behaviour, agency costs and ownership structure. Journal of Financial Economy, p. 305-360, 1976.
KAPLAN, J. M.;

DAKIN, L. S.;

SMOLIN, M. R.

Living with the organizational sentencing guidelines. California Management Review, v. 36, n. 1, Fall 1993.

LEWIS, A.;

WÄRNERYD, K-E.

The longstanding interest in business ethics. In: LEWIS, A.; WÄRNERYD, K-E. Ethics and economic affairs. London: Routledge, 1994.

MIGLIACIO FILHO, F. R.

Reflexões sobre o homem e o trabalho. Revista de Administração de Empresas, v. 34, n. 2, p. 18-32, abr./jun. 1994.

MILGROM, P.;

ROBERTS, J.

Economics, organization and management. Englewood Cliffs, NJ: Prentice-Hall, 1992.

NORTH, D. C.

Institutions, institutional change and economic performance. Cambridge: Cambridge University Press, 1990. 
PETRICK, J. A.;

QUINN, J. F.

Integrity capacity as a frame of reference for business ethics decision making in latin america. In: CONGRESSO DE ÉTICA, NEGÓCIOS E ECONOMIA NA AMÉRICA LATINA (CENE), 1., 1988, São Paulo. Anais... São Paulo: Fundação Getúlio Vargas, 1988.

PINHEIRO MACHADO, C. A. P. Responsabilidade social corporativa e agregação de valor para as organizações. São Paulo, 2002. Tese (Doutorado) Faculdade de Economia, Administração e Contabilidade, Universidade de São Paulo.

POSNER;

RASMUSEN.

Creating and enforcing norms, with special reference to sanctions. Indiana University's workshop in political theory and policy analysis, 1999.

ROSANSKY, L. M. H.

Moral and ethical dimensions of managing a multinational business.

In: LEWIS, A.; WÄRNERYD, K-E. (Eds.). Ethics and economic affairs. London: Routledge, 1994.

SEN, A.

On ethics and economics. Oxford: Blackwell, 1987.
SIMON, H.

Decision and organization. New York: American Elsevier, 1947.

Administrative behaviour. New York: MacMillan, 1972a.

Theories of bounded rationality. In: MCGUIRE, C.B.; RADNER, R. (Eds.). Decision and organization. New York: American Elsevier, 1972b.

SMITH, A.

The wealth of nations. Chicago: The University of Chicago Press, 1976.

TOMER, J. F.

Social responsibility in the human firm: towards a new theory of the firm's external relationships. In: LEWIS, A.; WÄRNERYD, K-E. (Eds.). Ethics and economic affairs. London: Routledge, 1994.

WIELAND, J.

Economy and ethics in functionally differentiated societies. In: LEWIS, A.; WÄRNERYD, K-E. (Eds.). Ethics and economic affair. London: Routledge, 1994.

WILLIAMSON, O.

The economic institutions of capitalism. New York: The Free Press, 1975.

The mechanisms of governance. Oxford: Oxford University Press, 1996. 